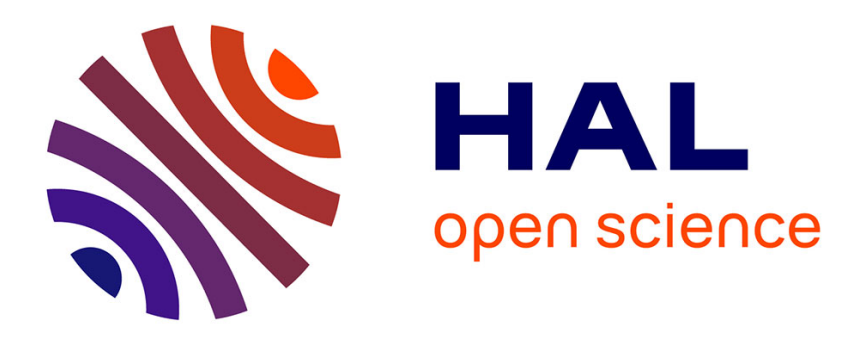

\title{
Proposition of a general yield function in geomechanics
}

Siegfried Maïolino

\section{To cite this version:}

Siegfried Maïolino. Proposition of a general yield function in geomechanics. Comptes Rendus Mécanique, 2005, 333, pp.279-284. 10.1016/j.crme.2004.11.008 . hal-00111444

\section{HAL Id: hal-00111444 \\ https://hal.science/hal-00111444}

Submitted on 19 Jan 2018

HAL is a multi-disciplinary open access archive for the deposit and dissemination of scientific research documents, whether they are published or not. The documents may come from teaching and research institutions in France or abroad, or from public or private research centers.
L'archive ouverte pluridisciplinaire $\mathbf{H A L}$, est destinée au dépôt et à la diffusion de documents scientifiques de niveau recherche, publiés ou non, émanant des établissements d'enseignement et de recherche français ou étrangers, des laboratoires publics ou privés. 


\title{
Proposition of a general yield function in geomechanics
}

\author{
Siegfried Maïolino a,b \\ a École polytechnique, laboratoire de mécanique des solides, 91128 Palaiseau cedex, France \\ ${ }^{\mathrm{b}}$ Centre d'études techniques de l'équipement de Lyon, laboratoire régional de Lyon - mécanique des roches, \\ 25, avenue François-Mitterrand, case numéro 1, 69674 Bron cedex, France
}

A general smooth and convex yield function is proposed, able to model the particular behavior of geomaterials, particularly rock materials that are characterized by a linear or parabolic Mohr's envelope, and a particular shape in the deviatoric plane. These characteristics are defined by two functions: the equation of the criterion in the meridian plane and the extension ratio, which are integrated in a general equation ensuring convexity and smoothness of the yield function, whatever the characteristic functions. This expression is interesting, because it allows a straightforward development of a constitutive model based on triaxial tests, in extension and compression. It also allows the development of smooth criteria corresponding to the MohrCoulomb criterion and the Hœk-Brown criterion, the latter typical of rock mechanics.

Proposition d'une fonction de charge générale en géomécanique. Un critère général lisse et convexe est proposé pour modéliser le comportement particulier des géomatériaux, particulièrement les roches qui possèdent une enveloppe de Mohr linéaire ou parabolique et une forme particulière dans le plan déviatorique. Ces caractéristiques sont définies par deux fonctions : l'équation du critère dans le plan méridien principal et le ratio d'extension. Ces deux fonctions sont intégrées dans une équation garantissant le caractère régulier et convexe de la fonction de charge indépendamment des fonctions caractéristiques. Cette expression est intéressante car elle permet ainsi la constitution directe d'un modèle à partir de tests triaxiaux, en extension et compression. Elle permet également le développement des formes régularisées correspondant au critère de Mohr-Coulomb et au critère de Hœk-Brown ce dernier étant propre à la mécanique des roches.

Keywords: Soils; Rocks; Yield function; Criterion; Constitutive model; Hœk-Brown; Mohr-Coulomb

Mots-clés : Sols ; Roches ; Fonction de charge ; Critère ; Loi de comportement ; Hok-Brown ; Mohr-Coulomb

E-mail address: siegfried.maiolino@equipement.gouv.fr (S. Maïolino). 


\section{Introduction ${ }^{1,2}$}

Apart from their inability to stand tensile conditions, one of the particularities of geomaterials, from a mechanical point of view, is the dependency of their strength on the confining pressure. The first criterion taking into account this property is known as the Mohr-Coulomb criterion whose intrinsic curve is a straight line. However, many rocks present a parabolic Mohr's envelope. In order to take into account this characteristic many criteria have be developed since the 1960s [1]; one of the best known is the Hœk-Brown criterion [2] (10), which has been developed so it can be used for a wide range of rocks. Like Mohr Coulomb, it presents corners, making it difficult to implement.

Another experimental characteristic of soils, rocks, mortar and concrete, is a particular shape in the deviatoric plane: triangular with smoothly rounded corners. Circular criteria, such as Drucker Prager, do not take into account this particular characteristic. Some smooth uncircular criteria, initially developed for cohesionless soils, can be used in rock mechanics, such as the modified Lade model [3], and the Matsuoka-Nakai model; both are expressed as functions of the polynomial invariants of the stress tensor.

The broad outline of this work is to realize a global smooth and convex yield function whose parameters can be easily identified from experiments. Moreover, it should be of use on different type of rocks.

\section{Polar decomposition of yield criterion}

When the mean stress $\sigma_{m}$ is constant, a yield surface can be reduced to its representation in the deviatoric plane: this shape generally reflects the smoothness of a criterion, sensitivity to extension, and convexity. Any isotropic yield surface can be represented in a unique manner by the mean stress and the deviatoric stress invariants $\left(J_{2}=\frac{1}{2} \operatorname{tr}\left(\underline{s}^{2}\right), J_{3}=\frac{1}{3} \operatorname{tr}\left(\underline{s}^{3}\right)\right)$. It can be useful to replace the third invariant, by the Lode angle $\theta$ :

$$
-\frac{\pi}{6} \leqslant \theta=\frac{1}{3} \arcsin \left(\frac{-3 \sqrt{3}}{2} \frac{J_{3}}{{\sqrt{J_{2}}}^{3}}\right) \leqslant \frac{\pi}{6}
$$

The set $\left(\sqrt{J_{2}}, \theta\right)$ can define polar coordinates in one sixth of the deviatoric plane, which is sufficient. It turns out that a yield surface admits an equivalent polar expression [4]:

$$
\sqrt{J_{2}}=\sigma^{+} g_{p}(\theta)
$$

- The deviatoric radius: $\sigma^{+}\left(\sigma_{m}\right)=\sqrt{J_{2}} / \theta=\frac{\pi}{6}$, gives the yield function in the meridional plane $\left(\sigma_{m}, \sqrt{J_{2}}\right)$, for $\theta=\frac{\pi}{6}$. This value of the Lode angle corresponds to the condition of a classical triaxial test, or compressive triaxial test $\left(\sigma_{\mathrm{I}}=\sigma_{\mathrm{II}}>\sigma_{\mathrm{III}}\right)$;

- the function $g_{p}(\theta)$ is the shape function of the yield function in the deviatoric plane. We have $\left(g_{p}\left(\frac{\pi}{6}\right)=1\right)$. It gives directly the value of the extension ratio $g_{p}\left(-\frac{\pi}{6}\right)=L_{S}$ which is discussed in more details in Section 3.2. This value is equal or lower to one for geomaterials.

The shape function of a smooth criterion must satisfy the following condition:

$$
\frac{\partial g}{\partial \theta}\left(\frac{\pi}{6}\right)=\frac{\partial g}{\partial \theta}\left(-\frac{\pi}{6}\right)=0
$$

\footnotetext{
1 Stress sign convention: Traction stresses are positive, and the principal stresses ordered as follows: $\sigma_{\mathrm{I}} \geqslant \sigma_{\mathrm{II}} \geqslant \sigma_{\mathrm{III}}$.

2 Software used: Mathematica ${ }^{\circledR}$ was used in Sections 4 and 5.
} 
In order to ensure the convexity of the criterion, some conditions must be verified. A simple graphic condition is that $L_{S}$ must be greater than $\frac{1}{2}$ (for smooth criterions (3), we necessarily have: $L_{S}>\frac{1}{2}$ ). Assuming that condition, it should be verified that the shape function is convex:

$$
J(\theta)=\left|\begin{array}{cc}
\frac{\mathrm{d}^{2} g}{\mathrm{~d}^{2} \theta}-g & 2 \frac{\mathrm{dg}}{\mathrm{d} \theta} \\
\frac{\mathrm{dg}}{\mathrm{d} \theta} & g
\end{array}\right| \geqslant 0
$$

Convexity of the deviatoric radius and of the shape function ensure convexity of the yield function [5].

\section{Characteristic functions of the behavior of a rock material}

These two functions are used to define important characteristics of rocks. They are supposed to be smooth and convex.

\subsection{Deviatoric radius}

This function is easy to define, because it can be deduced from triaxial tests that are common in geotechnics. Where the shape is straight or parabolic, the deviatoric radius function used can be the Mohr-Coulomb or HokBrown.

\subsection{Definition of the extension ratio}

Its value is directly linked to the deviatoric shape of a yield surface. However, this ratio has also a physical meaning and can be determined from experiment: under a same average stress, the yield value of $\sqrt{J_{2}}$ would be lower in extension than in compression. The condition $\theta=-\frac{\pi}{6}$ corresponds indeed to extension triaxial tests $\left(\sigma_{\mathrm{I}}>\sigma_{\mathrm{II}}=\sigma_{\mathrm{III}}\right)$ (compressive stresses are negative), which can be performed with the same triaxial device as the compression triaxial test.

$$
L_{S}=\frac{\sqrt{J_{2}}(\theta=-\pi / 6)}{\sqrt{J_{2}}(\theta=\pi / 6)}=\frac{\left(\sigma_{\mathrm{I}}-\sigma_{\mathrm{III}}\right)(\text { extension })}{\left(\sigma_{\mathrm{I}}-\sigma_{\mathrm{III}}\right)(\text { compression })}
$$

While this value can be independent from the mean stress (like in Mohr-Coulomb), some rocks offer a shape of their yield surface changing from triangular to circular as the mean stress increases [6], i.e. $L_{S}$ increases from 0.5 to 1 . The ratio function must be chosen so that $\left.\left.L_{S}\left(\sigma_{m}\right) \in\right] 0.5,1\right]$. It is constant or an increasing function of $-\sigma_{m}$.

\section{General yield function}

The proposed yield function (6) was intended to be a smooth convex yield function, defined by the deviatoric radius and an extension ratio $\left.\left.\left(L_{S}\left(\sigma_{m}\right) \in\right] 0.5,1\right]\right)$ (Fig. 1). Another requirement was to realize a simple yield function. So, it was decided not to define another shape function of the Lode angle, but to seek for a direct expression of the mean stress and of the deviatoric stress invariants $J_{2}, J_{3}$. By the mean of the polar decomposition it gives a third degree equation whose the shape function is solution. It was not necessary to give an explicit form of the shape function, but to impose its value at $\frac{\pi}{6}$ and $-\frac{\pi}{6}$, and (3) and (4) lead to the value of the coefficient of this equation. When the deviatoric radius and the extension ratio are known, the following equation defines a new yield function, integrating the two characteristic functions:

$$
f(\underline{\underline{\sigma}})=\frac{3}{2} \sqrt{3}\left(1-L_{S}\right) J_{3}+\left(L_{S}^{2}+1-L_{S}\right) \sigma^{+} J_{2}-\sigma^{+3} L_{S}^{2}
$$




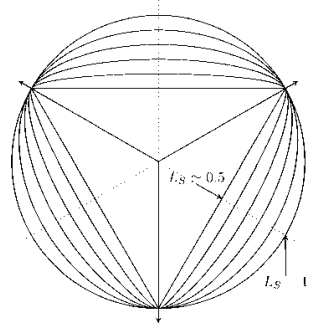

Fig. 1. Influence of $L_{S}$ on the shape of the yield function.

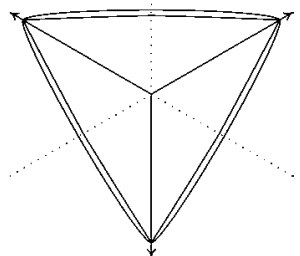

(a)

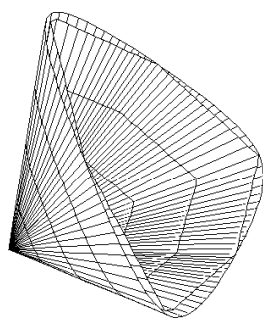

(a)

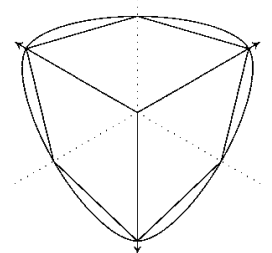

(b)

Fig. 2. Mohr-Coulomb criterion and smooth version $\left(\phi=35^{\circ}\right)$. (a) Stress space representation, (b) shape functions.

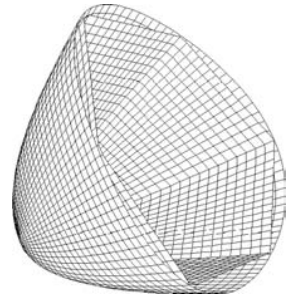

(b)

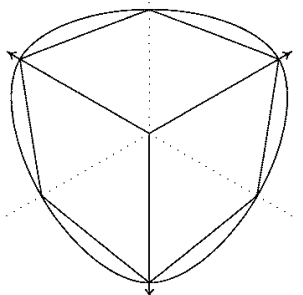

(c)

Fig. 3. Hœk-Brown criterion and smooth version. (a) $P_{i}=0.01$, (b) stress space representation, (c) $P_{i}=\frac{3}{4}$.

Considering the polar decomposition of the yield surface (2), we can say from (6) that the shape function is solution of the following equation:

$$
g_{p}^{3}(\theta) \sin 3 \theta\left(-1+L_{S}\right)+\left(1-L_{S}+L_{S}^{2}\right) g_{p}^{2}(\theta)-L_{S}^{2}=0
$$

The particular values $\left(g_{p}\left(\frac{\pi}{6}\right)=1, g_{p}\left(-\frac{\pi}{6}\right)=L_{S}\right)$ of the shape functions are solutions of (7). Derivations of (7) permit to verify smoothness (3) and convexity for $L_{S}>0.5$ as (4) can be reduced to $J(\theta)=\left(2-3 L_{S}-3 L_{S}^{2}+2 L_{S}^{3}\right)$.

\section{Some particular forms of the criterion}

The smooth versions of two common geomechanical criteria, Mohr-Coulomb (Fig. 2) and Hok-Brown (Fig. 3), are proposed. As the principal stresses can be written as function of $\sqrt{J_{2}}$ and $\theta$, the polar decomposition of those function can be made, after having replaced the principal stresses by their expression as function of $\sigma_{m}, \sqrt{J_{2}}$, and $\theta$ [4], giving their deviatoric radius, and extension ratios.

\subsection{Mohr-Coulomb}

The deviatoric radius and extension ratio in this case are the following, with $H=\frac{C}{\tan \phi}$ :

$$
\begin{aligned}
\sigma^{+} & =\frac{2 \sqrt{3} \sin \phi\left(H-\sigma_{m}\right)}{3-\sin \phi} \\
L_{S} & =\frac{3-\sin \phi}{3+\sin \phi}
\end{aligned}
$$

In this case, the yield function is equal to the one of Matsuoka-Nakai criterion. It is interesting, because when using the notion of 'spatially mobilized plane' - which averages the friction angles, instead of the octahedral 


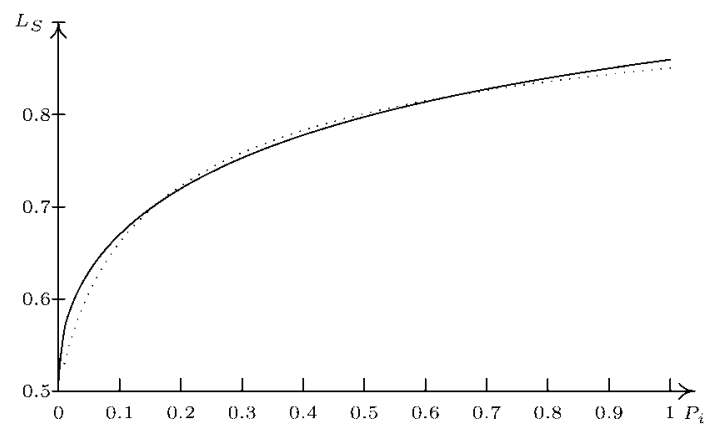

Fig. 4. $L_{S}^{\mathrm{HB}}\left(\right.$ dotted) and approched $L_{S}$.

plane, the Matsuoka-Nakai criterion corresponds to the Mohr-Coulomb criterion, just as the Von Mises criterion corresponds to the Tresca criterion [7].

\subsection{Hok-Brown}

The Hok-Brown criterion can be written as follows, with $R_{c}$ the uniaxial strength of the intact rock, $m_{b}$ the value the Hok-Brown constant for intact rock (value between 4 and 33), and $s$ a positive parameter, equal to 1 for intact rock, lower for fractured rock, which can be used as a softening variable.

$$
f(\underline{\underline{\sigma}})=\left(\sigma_{\mathrm{I}}-\sigma_{\mathrm{III}}\right)-R_{c} \sqrt{s-m_{b} \frac{\sigma_{\mathrm{I}}}{R_{c}}}
$$

We consider the following functions to define the criterion, using the scaled internal pressure [8]: $P_{i}=s / m_{b}^{2}-$ $\sigma_{m} /\left(m_{b} R_{c}\right)$ whose value is strictly positive (for common stress states, it can be considered lower than one).

$$
\begin{aligned}
\sigma^{+} & =\frac{m_{b} R_{c}}{4 \sqrt{3}} 2 \frac{-1+\sqrt{1+36 P_{i}}}{3} \\
L_{S} & =1-0.49 \mathrm{e}^{-1.25 \sqrt{P_{i}}}
\end{aligned}
$$

This extension ratio is a sufficiently close approximation (Fig. 4) of the one from the original criterion $\left(L_{S}^{\mathrm{HB}}=\right.$ $\left.2\left(-1+\sqrt{1+9 P_{i}}\right) /\left(-1+\sqrt{1+36 P_{i}}\right)\right)$. This permits to realize a smooth Hœk-Brown criterion, preserving its parabolic character, and its particular deviatoric stress (Fig. 3).

\subsection{Comparison with explicit shape functions}

The proposed yield function is a direct function of the third deviatoric invariant, and thus does not require the calculation of the Lode angle, that explicit shape functions require. However, it is interesting here to compare it with those forms.

The simplest explicit function [9] (13) is convex only for $L_{S} \in\left[\frac{7}{9}, 1\right]$, which corresponds when seeking correspondence with a Mohr-Coulomb criterion, to values of the friction angle lower than 22 degrees.

$$
g_{p}(\theta)=\frac{2 L_{S}}{\left(1+L_{S}\right)-\left(1-L_{S}\right) \sin 3 \theta}
$$


The William-Warnke [10] shape function (14), used for concrete materials, is convex for any value of $L_{S}$ greater than 0.5 , but is more complex. It is not solution of (7), but is relatively near, as the values obtained are all lower than 0.02 .

$$
g_{p}(\theta)=\frac{2\left(1-L_{S}^{2}\right) \cos \left(\theta+\frac{\pi}{6}\right)+\left(2 L_{S}-1\right) \sqrt{4\left(1-L_{S}^{2}\right) \cos ^{2}\left(\theta+\frac{\pi}{6}\right)+5 L_{S}^{2}-4 L_{S}}}{4\left(1-L_{S}^{2}\right) \cos ^{2}\left(\theta+\frac{\pi}{6}\right)+\left(2 * L_{S}-1\right)^{2}}
$$

Another explicit shape function has been proposed by Bigoni and Piccolroaz [5], which is not function of $L_{S}$ but of two parameters $\beta$ and $\gamma$ :

$$
g_{p}(\theta)=\frac{\cos (\beta \pi / 6-(\arccos (-\gamma)) / 3)}{\cos (\beta \pi / 6-(\arccos (-\gamma \sin 3 \theta)) / 3)}
$$

This shape function is a numerical solution of (7), for $\beta=0, \gamma=\cos \left(3 \arccos \left(\frac{\sqrt{3}}{2 \sqrt{1-L_{S}+L_{S}^{2}}}\right)\right)$.

\section{Conclusion}

The general form of the proposed yield function ensures its ability to model different behavior of geomaterials, as has been shown for the correspondence with the criteria of Mohr-Coulomb or Hok-Brown allowing us in this last case to produce a smooth criterion for rocks, with a parabolic intrinsic curve, and a complex extension ratio. The characteristic functions: deviatoric radius and extension ratio, can be determined using a common triaxial device. Its smoothness and convexity are also interesting, when using finite elements methods.

\section{Acknowledgements}

The development of this criterion is part of a work supported by the French Ministry for infrastructure, transport, housing, tourism and the sea.

I also want to thank Habibou Maïtournam, associate professor at the École Polytechnique, for his careful help and encouragements, throughout the time I spent at the LMS.

\section{References}

[1] X.D. Pan, J.A. Hudson, A simplified three dimensional Hoek-Brown yield criterion, in: Rock Mechanics and Power Plants, ISRM Symposium, Madrid, 1988, pp. 95-103.

[2] E. Hoek, E.T. Brown, Empirical Strength criterion for rock masses, J. Geotech. Engrg. ASCE 106 [GT9] (1980) 1013-1035.

[3] P.V. Lade, Elasto-plastic stress-strain theory for cohesionless soil with curved yield surfaces, Int. J. Solids Struct. 13 (1977) $1019-1035$.

[4] O.C. Zienkiewicz, G.N. Pande, Some useful forms of isotropic yield surfaces for soil and rock mechanics, in: Numerical Methods in Soil and Rock Mechanics, Karlsruhe, September 1975, pp. 3-16.

[5] D. Bigoni, A. Piccolroaz, Yield criteria for quasibrittle and frictional materials, Int. J. Solids Struct. 41 (2004) 2855-2878.

[6] M.K. Kim, P.V. Lade, Modeling rock strength in three dimensions, Int. J. Rock Mech. Min. Sci. Abstracts 21 (1) (1984) 21-33.

[7] H. Matsuoka, T. Nakai, Relationship among Tresca, Mises, Mohr-Coulomb and Matsuoka-Nakai failure criteria, Soils Foundations 25 (4) (1985) $123-128$.

[8] C. Carranza-Torres, C. Fairhurst, The elasto-plastic response of underground excavations in rock masses that satisfy the Hœk-Brown failure criterion, Int. J. Rock Mech. Min. Sci. 36 (1999) 777-809.

[9] J. Argyris, G. Faust, J. Szimmat, E.P. Warnke, K.J. William, Recent developments in the finite element analysis of PCRV, in: 2nd Int Conf. SMIRT, Berlin, Nuclear Engineering and Design 28 (1) (July 1974) 42-75.

[10] K. William, E.P. Warnke, Constitutive models for the triaxial behavior of concrete, in: International Association of Bridge and Structural Engineering (IABSE) Seminar on “Concrete Structures Subjected to Triaxial Stresses”, Bergamo, 19, 1975, pp. 1-30. 